\title{
Evaluation of antioxidant activities and haematological effects of Asystasia gangetica leaf extract in monosodium glutamate-treated rats
}

\author{
Robert Uroko ${ }^{1, *}$, Amarachi Agbafor ${ }^{1}$, Simeon Egba ${ }^{1}$, Chinedu NwUKe $^{1}$, ANd Sharon \\ KALU-KALU ${ }^{1}$ \\ ${ }^{1}$ Michael Okpara University of Agriculture, PMB 7267, Umudike, Abia State, Nigeria \\ *Corresponding author: ir.uroko@mouau.edu.ng
}

Published: December 25, 2021

Received: January 12, 2021

Accepted: May 6, 2021

Published on-line: September 1, 2021

\begin{abstract}
This study evaluated antioxidant activities and haematological effects of methanol extract of Asystasia gangetica leaves (MEAG) on monosodium glutamate (MSG) treated rats. Forty-two male Wistar rats randomly distributed into 7 groups $(n=6)$ were used for the study. Groups 1-3 were the normal control, MSG control, and positive control respectively whereas groups 4-5 were the extract controls, and groups 6-7 were the curative groups. All the treatments were administered orally and standard analytical methods were used for analyses. The results showed that MEAG is a rich antioxidants source and contains phenolics, flavonoids and beta-carotene in high concentrations. The extract showed concentration-dependent increases in ferric reducing antioxidant power, DPPH (2,2-diphenyl-1-picrylhydrazyl) and nitric oxide radicals scavenging activities but relatively lower than their respective controls. The MSG administration caused significant $(P<0.05)$ reductions in the glutathione peroxidase (GPx), superoxide dismutase (SOD) and catalase (CAT) activities but significantly $(P<0.05)$ increased the malondialdehyde (MDA) concentrations in the MSG control rats. The MSG administration also caused significant $(\mathrm{P}<0.05)$ reductions in the haemoglobin $(\mathrm{Hb})$ concentration, packed cell volume (PCV), red blood cell (RBC) and white blood cell (WBC) counts of the MSG control relative to the normal control. Treatment with MEAG significantly elevated GPx, SOD, and CAT activities; haematological indices and significantly reduced MDA levels in the extract controls, and curative groups treated with a high dose of MSG. These findings show that methanol extract of $A$. gangetica leaves is rich in antioxidants that could prevent oxidative stress and improves the haematological profile of MSG treated rats.
\end{abstract}

Key words: Antioxidants; oxidative stress; antioxidant enzymes; free radicals; lipid peroxidation

http://dx.doi.org/10.5937/leksir2141005U

\section{INTRODUCTION}

Monosodium glutamate (MSG) is one of the oldest available food condiments of amino acid origin that improves the taste, flavor, and palatability of food. However, there are increasing concerns that it could elicit severe adverse human health effects due to the emerging scientific evidence on its toxicity potentials. It is extensively used as a food additive in countries like China and Japan in which many researchers have attributed the increasing cardiovascular diseases in these to it without any scientific evidence in their support (Singh et al., 2011). Findings from various scientific studies involving animal models have demonstrated that monosodium glutamate induces liver and kidney injuries, lipid peroxidation, cytotoxicity, metabolic and haematological disorders mainly by initiating oxidative stress and depleting the levels of circulating endogenous antioxidant enzymes (Khalaf and Arafat, 2015; Ugur Calis et al., 2016). The antioxidant enzymes such as superoxide dismutase (SOD), catalase (CAT), and glutathione peroxidase (GPx) function to quench free radicals and protect tissues, organs, nucleic acids and other biomolecules in the body from oxidative damage but these enzymes and other proteins including enzymes are usually deactivated irreversibly under oxidative stress (Al-Harbi et al., 2014). Antioxidant vitamins including vitamins $C$ and $E$ have been used in the management of MSG induced oxidative stress and its associated adverse health effects with almost total recovery from MSG toxicity. Plant extracts rich in antioxidant vitamins and other phytoconstituents with antioxidative activities could be 
more effective in the management of oxidative stress and MSG toxicity (Al-Harbi et al., 2014).

scavenge and attenuate free radicals and protect tissues, organs, nucleic acids, and other biomolecules in the body from oxidative damage but these enzymes and other proteins or enzymes containing iron are usually deactivated irreversibly under oxidative stress (Al-Harbi et al., 2014). Antioxidant vitamins including vitamins $C$ and $E$ have been used in the management of MSG induced oxidative stress and its associated adverse health effects with almost total recovery from MSG toxicity but plant extracts rich in antioxidant vitamins and other phytoconstituents with antioxidative activities could be more effective in the management of oxidative stress and MSG toxicity.

Asystasia gangetica [(Linn.) T. Anderson] commonly called "Chinese violet" is a member of the Acanthaceae family known for its violet flower colouration. It has been reported that it contains some phytochemicals like alkaloids, flavonoids, tannins, phenols, steroids and terpenoids which could contribute to its bioactivities (Sama et al., 2013). The A. gangetica leaf extracts have been reported to be effective in the management of asthma (Akah et al., 2003), stomachache, diabetes mellitus, rheumatism, and hypertension (Mugabo and Raji, 2013). This study was aimed at evaluating the antioxidant activities and haematological effects of methanol extract of $A$. gangetica leaves (MEAG) on monosodium glutamate treated rats.

\section{MATERIALS AND METHODS}

\subsection{Collection of plant materials}

Asystasia gangetica leaves were collected from the Forestry Research Institute of Nigeria, Eastern Station, located at Ahia Eke Ndume in Umuahia, Abia State Nigeria. The plant sample was identified and authenticated as A. gangetica with the voucher number: 2694-5 (press 1899) by the Herbarium unit of the Department of Forestry College of Natural Resources and Environmental Management, Michael Okpara University of Agriculture, Umudike.

\subsection{Chemical and reagents}

The chemicals and reagents used in this study were of analytical standard. The methanol, gallic acid, 2,2-diphenyl-1picrylhydrazyl (DPPH), nitric oxide and rutin were sourced from Sigma-Aldrich (USA), while sodium carbonate and iron (III) chloride were from Guangdong Guanghua Sci-Tech Company Ltd, India. The Folin and Ciocatteu's phenol reagent, ascorbic acid, meta-phosphoric acid and beta-carotene were obtained from LOBA Chemie Laboratory Reagent and Fine Chemicals, India. Silymarin was from Micro Labs Limited (India), while monosodium glutamate (MSG) was obtained from Ajinomoto, Japan.

\subsection{Preparation and extraction of $\boldsymbol{A}$. gangetica leaves}

The A. gangetica leaves were handpicked to remove dirt such as plant debris and rinsed in running clean tap water. The leaves were air-dried at room temperature for three weeks and pulverized into a coarse powder with aid of a mechanical grinder and weighed. A quantity, of $414 \mathrm{~g}$ of the coarsely ground $A$. gangetica leaves was macerated in cold $1.5 \mathrm{~L}$ of absolute methanol for 3 days with mild shaking at regular intervals. It was then filtered with a Whatman No 1 filter paper and the filtrate was concentrated in a water bath at $45^{\circ} \mathrm{C}$ till the methanol has evaporated completely. The concentrated filtrate was weighed and the percentage yield of the extract was calculated.

\subsection{Experimental animals}

Forty-two male Wistar albino rats weighing 140 - $150 \mathrm{~g}$ were sourced from the Animal House of Faculty of Biological Science, University of Nigeria, Nsukka (UNN), and allowed to adapt to the new environmental condition with unlimited access to standard grower feed and drinking water ad libitum for 21 days before the commencement of the full study.

\subsection{Experimental design}

This study adopted a completely randomized design, which comprises group 1-7 with each group having 6 rats as follows:

Group 1 Normal control rats that received $2 \mathrm{ml} / \mathrm{kg}$ distilled water/day for 14 days.

Group 2 Monosodium glutamate (MSG) control administered $8 \mathrm{~g} / \mathrm{kg}$ MSG on the day 1 and after $24 \mathrm{~h}$ treated with $2 \mathrm{ml} / \mathrm{kg}$ distilled water/day for 12 days before further administration of 8 $\mathrm{g} / \mathrm{kg}$ MSG on $14^{\text {th }}$ day.

Group 3 Positive control rats administered $8 \mathrm{~g} / \mathrm{kg}$ MSG on day 1 and after $24 \mathrm{~h}$, treated with $100 \mathrm{mg} / \mathrm{kg}$ silymarin/day for 12 days before further administration of $8 \mathrm{~g} / \mathrm{kg}$ MSG on the $14^{\text {th }}$ day.

Group 4 Rats received $2 \mathrm{ml} / \mathrm{kg}$ distilled water on day 1 and after $24 \mathrm{~h}$ treated with $200 \mathrm{mg} / \mathrm{kg}$ MEAG/day for 12 days beffore the administration of $2 \mathrm{ml} / \mathrm{kg}$ distilled water on th $14^{\text {th }}$ day.

Group 5 Rats received $2 \mathrm{ml} / \mathrm{kg}$ distilled water on day 1 and after $24 \mathrm{~h}$ treated with $500 \mathrm{mg} / \mathrm{kg}$ MEAG/day for 12 days beffore the administration of $2 \mathrm{ml} / \mathrm{kg}$ distilled water on th $14^{\text {th }}$ day.

Group 6 Rats received $8 \mathrm{~g} / \mathrm{kg}$ MSG on day 1 and after $24 \mathrm{~h}$, treated with $200 \mathrm{mg} / \mathrm{kg}$ MEAG / day for 12 days before the administration of $8 \mathrm{~g} / \mathrm{kg}$ MSG on the $14^{\text {th }}$ day.

Group 7 Rats received $8 \mathrm{~g} / \mathrm{kg}$ MSG on day 1 and after $24 \mathrm{~h}$, treated with $500 \mathrm{mg} / \mathrm{kg}$ MEAG/day for 12 days before the administration of $8 \mathrm{~g} / \mathrm{kg}$ MSG on the $14^{\text {th }}$ day.

Groups 4-5 were the extract groups and groups 6-7 served as the curative groups. All the treatments were administered to the rats orally. After 14 days of treatment, the rats fasted overnight and blood samples were collected from the rats on the $15^{\text {th }}$ day for the antioxidant and haematological analyses.

\subsection{Determination of antioxidants compositions and in vitro antioxidant activities}

The flavonoids content in the methanol extract of $A$. gangetica leaves was determined according to the method described by Harborne (1998) while the amount of total phenolic contents in the extract was quantified using the method of Trease and Evans (2002). Also, the level of $\beta$-carotene and lycopene present in the extract was determined following the methods of (Nagata and Yamashita, 1992). The amount of vitamin C in the methanol extract of A. gangetica leaves was determined in line with the method of (Omaye et al., 1979). The ferric reducing antioxidant power (FRAP) of the methanol extract of $A$. gangetica leaves was determined with the method of 
Benzie and Strain (1996) while its ability to scavenge DPPH (2, 2-diphenyl-1-picrylhydrazyl) and nitric oxide free radicals were determined with methods of (Hatano et al., 1988) and (Marcocci et al., 1994) respectively.

\subsection{Analyses of in vivo antioxidant activities and haemato- logical parameters}

The glutathione peroxidase (GPx), superoxide dismutase (SOD), and catalase (CAT) activities were assayed using the methods of (Ursini et al., 1985), (Xin et al., 1991), and (Aebi, 1983), respectively. The malondialdehyde (MDA) concentration was determined according to the method described by (Wallin et al., 1993) while the haematological indices (haemoglobin, packed cell volume, red blood cell, and white blood cell counts) were determined using the methods of (Dacie and Lewis, 1991).

\subsection{Ethical approval}

This study adhered to the regulations of the Iranian Ethical Committee Guidelines for the use of animals in research and the study was approved by the Ethical Committee of the Department of Physiology and Pharmacology, College of Veterinary Medicine, Michael Okpara University of Agriculture, Umudike with the Reference Number: MOUAU/VPP/EC/18/003"

\subsection{Statistical Analysis}

The data were analyzed using one-way of variance (ANOVA) with the aid of Statistical Products and Service Solutions (SPSS) version 22. The means were compared using Duncan's multiple range comparison tests and the results were expressed as mean \pm standard deviation. The level of statistical significance was established at a $95 \%$ confidence level $(\mathrm{P}<0.05)$.

\section{RESULTS}

\subsection{Percentage yield}

The extraction of $414 \mathrm{~g}$ of coarsely ground A. gangetica leaves with methanol gave a $5.51 \%$ yield corresponding to $22.82 \mathrm{~g}$ of the methanol extract.

\subsection{Antioxidant contents of methanol extract of $\boldsymbol{A}$. gangetica leaves}

The concentrations of the antioxidants in the methanol extract of A. gangetica leaves showed that the antioxidant content decreased in the following order: phenolics > flavonoids > $\beta$-carotene $>$ vitamin $C>$ lycopene respectively (Table 1 ).

Table 1. Antioxidant components in methanol extract of Asystasia gangetica leaves

\begin{tabular}{lr}
\hline Antioxidant components & $\begin{array}{r}\text { Quantities } \\
{[\mathrm{mg} / 100 \mathrm{~g}]}\end{array}$ \\
\hline Total phenolics & $6800.9 \pm 4.73$ \\
Flavonoids & $442.6 \pm 0.13$ \\
$\beta$-carotene & $84.2 \pm 0.15$ \\
Lycopene & $46.4 \pm 0.03$ \\
Vitamin C & $51.9 \pm 0.06$ \\
\hline
\end{tabular}

\subsection{Ferric reducing antioxidant power (FRAP) of methanol} extract of Asystasia gangetica leaves

The mathanol extract of $A$. gangetica and used standards showed the concentration-dependent activity in FRAP assay for examined concentration range (Figure 1).

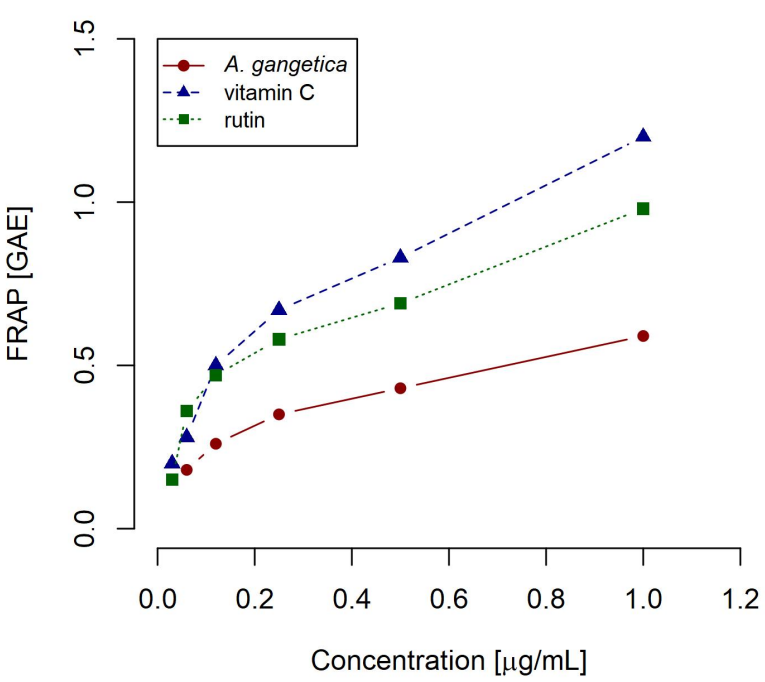

Fig. 1. Ferric reducing antioxidant power (FRAP) of methanol extract of $A$. gangetica leaves

\subsection{DPPH free radical scavenging activities of methanol extract of $\boldsymbol{A}$. gangetica leaves}

The DPPH assay showed that methanol extract of $A$. gangetica leaves possesses radical scavenging activity that increases with the increasing concentration of the extract (Figure 2). The DPPH free radical scavenging effects of the methanol extract of $A$. gangetica leaves were much reduced relative to the DPPH radical scavenging activities observed for vitamin $C$ at all the corresponding concentrations. The $\mathrm{IC}_{50}$ value which is the minimum concentration of antioxidant substance required to attain $50 \%$ inhibition of DPPH radicals indicated that the methanol extract of $A$. gangetica leaves has a lower activity $\left(\mathrm{IC}_{50}\right.$ value of $0.110 \mu \mathrm{g} / \mathrm{ml}$ ) when compared with vitamin C ( $\mathrm{IC}_{50}$ value of $0.038 \mu \mathrm{g} / \mathrm{ml}$ ).

\subsection{Nitric oxide free radical scavenging activities of methanol extract of $\boldsymbol{A}$. gangetica leaves}

The data in Figure 3 showed nitric oxide free radical scavenging activity of methanol extract of $A$. gangetica leaves which indicated a concentration-dependent increase in its percentage of nitric oxide inhibition similar to the nitric oxide inhibition effects exhibited by curcumin, a standard antioxidant. The $\mathrm{IC}_{50}$ of curcumin and methanol extract of $A$. gangetica leaves were 58 and $75 \mu \mathrm{g} / \mathrm{mL}$, respectively.

\subsection{Effects of methanol extract of $\boldsymbol{A}$. gangetica leaves on glu- tathione peroxidase activities of monosodium glutamate treated rats}

The glutathione peroxidase activities indicated a significant $(\mathrm{P}<0.05)$ reduction in the GPx activity of the MSG control relative to the normal control (Figure 4A). However, the GPx activities of the positive control, extract groups, and curative groups (MSG +200 , and MSG $+500 \mathrm{mg} / \mathrm{kg} /$ day of MEAG) 


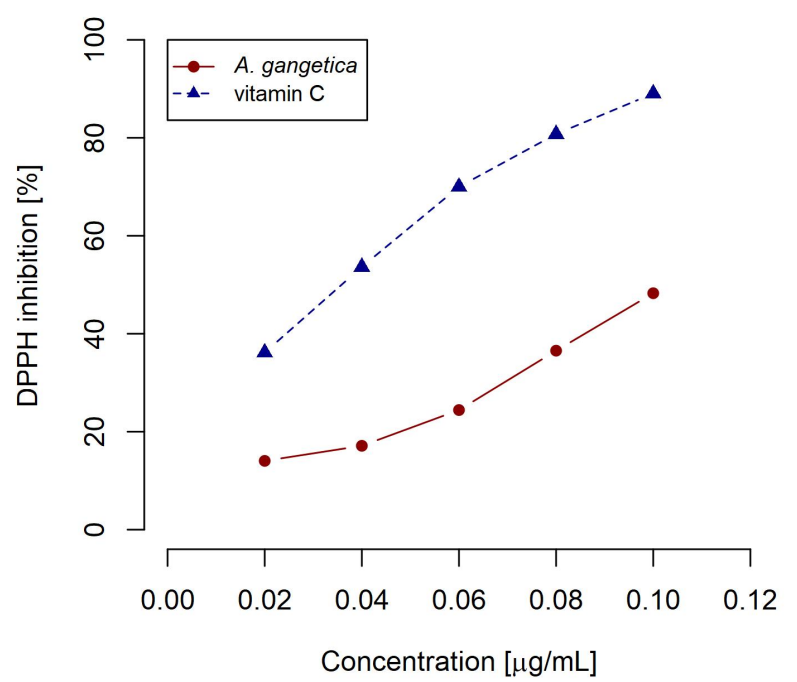

Fig. 2. DPPH free radical scavenging activities of methanol extract of $A$. gangetica leaves

significantly $(\mathrm{P}<0.05)$ increased when compared with the normal and MSG controls respectively. In like manner, the GPx activities of the extract groups, and curative groups showed significant $(\mathrm{P}<0.05)$ reductions relative to the positive control

\subsection{Effects of methanol extract of A. gangetica leaves on superoxide dismutase (SOD) activities of monosodium glutamate treated rats}

The SOD activities indicated significant $(\mathrm{P}<0.05)$ reductions in the SOD activities of the MSG control, positive control (group 3 ), and curative groups (groups 6 and 7) respectively when compared with the normal control (Figure 4B). On the other hand, the positive control, extract groups (groups 4 and 5), and curative groups showed significant $(\mathrm{P}<0.05)$ increases in the SOD activities when compared with the MSG control. It was further observed that the extract groups that received 200 and $500 \mathrm{mg} / \mathrm{kg} /$ day of MEAG only respectively indicated a significant $(\mathrm{P}<0.05)$ increase in the SOD activities relative to the positive control that MSG induced and treated with 100 $\mathrm{mg} / \mathrm{kg} /$ day of silymarin.

\subsection{Effects of methanol extract of Asystasia gangetica leaves on catalase (CAT) activities of monosodium glu- tamate treated rats}

The catalase activities in Figure $4 \mathrm{C}$ indicated a significant $(\mathrm{P}$ $<0.05)$ decrease in the catalase activities of the MSG control (group 2), positive control (group 3), and curative groups (groups 6 and 7) respectively relative to the normal control. However, the extract groups (groups 4 and 5) showed no significant $(\mathrm{P}<0.05)$ increase in catalase activities when compared with the normal control. However, the extract groups, positive control, and curative groups showed a significant $(\mathrm{P}<0.05)$ in crease in the catalase activities when compared with the MSG control. The extract groups showed a significant $(\mathrm{P}<0.05)$ increase in the catalase activities when compared with positive control treated with silymarin. Contrary, the curative group (group 6) treated with $200 \mathrm{mg} / \mathrm{kg} /$ day of MEAG showed a no significant $(\mathrm{P}>0.05)$ decrease in the catalase activities relative to the positive control.

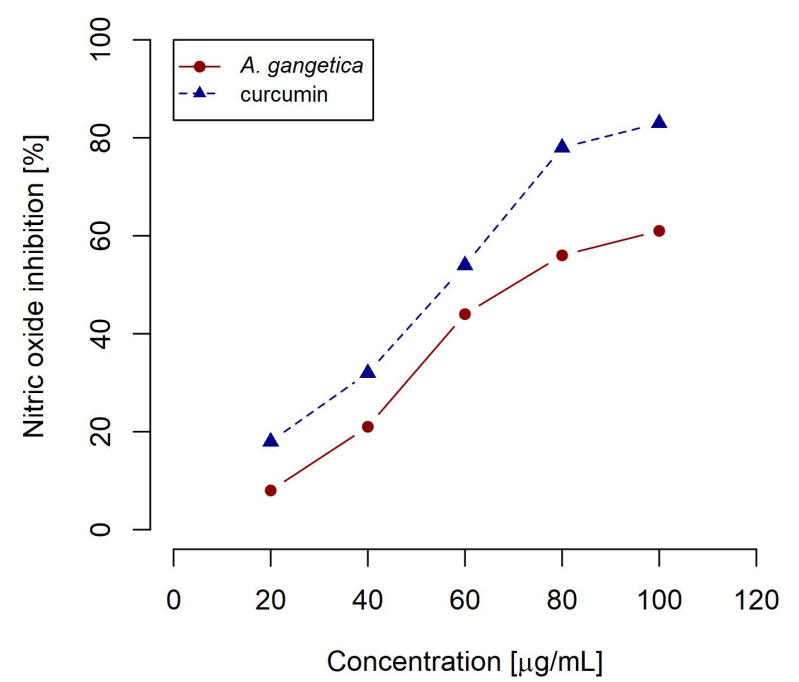

Fig. 3. Nitric oxide scavenging activity of methanol extract of $A$. gangetica leaves

\subsection{Effects of methanol extract of $\boldsymbol{A}$. gangetica leaves on malondialdehyde (MDA) concentration of monosodium glutamate treated rats}

The MDA concentrations of the MSG treated rats that received graded doses of methanol extract of $A$. gangetica leaves (MEAG) in Figure 4D indicated a significant $(P<0.05)$ increase in the MDA concentrations of the MSG control, positive control (group 3), and curative groups (groups 6 and 7) relative to the normal control. However, the positive control, extract groups (group 4 and 5), and the MEAG treated curative groups showed significant reductions in the MDA concentrations when compared with the MSG control. Furthermore, the extract groups and the curative groups had significantly $(\mathrm{P}<0.05)$ lower MDA concentrations relative to the positive control rats that received $100 \mathrm{mg} / \mathrm{kg} /$ day of silymarin.

\subsection{Effects of methanol extract of $\boldsymbol{A}$. gangetica leaves on the haematological indices of monosodium glutamate treated rats}

As shown in Table 2 the MSG control group had significantly lower $\mathrm{Hb}$ concentration compared to other groups. The $\mathrm{Hb}$ concentrations of MSG treated rats that received graded doses of MEAG were significantly $(\mathrm{P}<0.05)$ elevated relative to positive control rats treated with silymarin but there were no significant $(\mathrm{P}<0.05)$ differences in the $\mathrm{Hb}$ concentration of MEAG groups and normal control.

The values of percentage packed cell volume (Table 2) indicated significant $(\mathrm{P}<0.05)$ reductions in the $\mathrm{PCV}$ counts of the MSG control, and positive control treated with $100 \mathrm{mg} / \mathrm{kg}$ silymarin/day when compared with the PCV count of the normal control rats. The positive control, extract groups, and curative (MSG + 200 and $500 \mathrm{mg} / \mathrm{kg}$ MEAG/day) groups respectively had significantly $(\mathrm{P}<0.05)$ increased $\mathrm{PCV}$ counts relative to the MSG control. Similarly, the extract groups, and curative (MSG + 200, and MSG + $500 \mathrm{mg} / \mathrm{kg}$ MEAG/day) groups respectively had significantly $(\mathrm{P}<0.05)$ increased PCV counts when compared with the positive control.

The red blood cells (RBC) counts of the MSG control, positive control, rats that received $200 \mathrm{mg} / \mathrm{kg}$ MEAG/day, and MSG + $200 \mathrm{mg} / \mathrm{kg}$ MEAG/day respectively showed significantly $(\mathrm{P}<0.05)$ reductions in the $\mathrm{RBC}$ counts relative to the 
normal control (Table 2). However, the extract groups (200 and $500 \mathrm{mg} / \mathrm{kg} \mathrm{MEAG/day),} \mathrm{and} \mathrm{curative} \mathrm{groups} \mathrm{had} \mathrm{signif-}$ icantly $(\mathrm{P}<0.05)$ increased $\mathrm{RBC}$ counts when compared with the MSG control. Whereas, the rats that received $500 \mathrm{mg} / \mathrm{kg}$ MEAG/day only, and MSG + $500 \mathrm{mg} / \mathrm{kg}$ MEAG/day respectively showed significantly $(\mathrm{P}<0.05)$ elevated $\mathrm{RBC}$ counts relative to the positive control.

The white blood cell (WBC) counts in Table 2 indicated significant $(\mathrm{P}<0.05)$ reductions in the WBC counts of the MSG control, positive control, extract groups, and curative groups when compared with the normal control respectively. There was also, a significant $(\mathrm{P}<0.05)$ elevation in the WBC counts of the group 7 rats relative to the MSG and positive controls respectively.

\section{DISCUSSION}

Monosodium glutamate (MSG) is one of the commonly used food condiments in most countries of the world that many scientists have questioned the rationale behind its continued use due to overwhelming scientific evidence that it has adverse health implications such as oxidative damage that results in hepatic and kidney injuries among other adverse health consequences (Ugur Calis et al., 2016). The endogenous antioxidant enzymes like glutathione peroxidase (GPx), superoxide dismutase (SOD), and catalase (CAT) are critical components of the body's defence mechanisms that help to attenuate oxidative damage. The study was undertaken to evaluate the antioxidants and haematological effects of methanol extract of $A$. gangetica leaves on monosodium glutamate challenged rats. The high levels of antioxidant components in the methanol extract of $A$. gangetica leaves are indicative that the plants could possess potent antioxidant activities that could scavenge free radicals, reduce and or prevent oxidative stress-induced damage to organs, and macromolecules. The high antioxidant in the methanol extract of $A$. gangatica leaves correlated with the significant in vitro antioxidant activities exhibited by the plant extract and the elevated in vivo antioxidant enzymes activities of the MSG induced rats treated with graded doses of the extract. Plant extracts rich in sufficient amounts of antioxidants such as flavonoids, total phenols, vitamin $\mathrm{C}$, and lycopene exhibit high antioxidant activities that could efficiently scavenge free radicals and limit the extent of oxidative stress in line with the findings of (Jaeger and Cuny, 2016). These antioxidant components can donate or abstract electrons to neutralize and quench free radical-mediated attacks on biomolecules. Vitamin $C$ is a well-known antioxidant that helps recycles vitamin $E$ to ensure that it always has enough antioxidants to counter reactive free radicals and stabilizes the circulating antioxidant enzymes concentrations in the body. Flavonoids are polar compounds and possess high antioxidant properties that could effectively scavenge free radicals and prevents oxidative stress and plant extracts rich in flavonoids could play a key role in the prevention and management of oxidative stress-related diseases in line with the findings of (Kessler et al., 2010).

Ferric reducing antioxidant power (FRAP) is one of the most reliable models used to ascertain the levels of antioxidant activity exhibited by antioxidant compounds via the donation of electrons to the reactive free radical species. The concentrationdependent ferric reducing antioxidant power of the methanol extract of $A$. gangetica leaves correlate with the abundant antioxidant in the extract and suggest that $A$. gangetica leaves have high antioxidant potentials.

This is similar to the findings of (Omonije et al., 2020). The lower ferric reducing antioxidant power exhibited by the methanol extract of $A$. gangetica leaves relative to vitamin $C$ and rutin respectively indicated that some non-
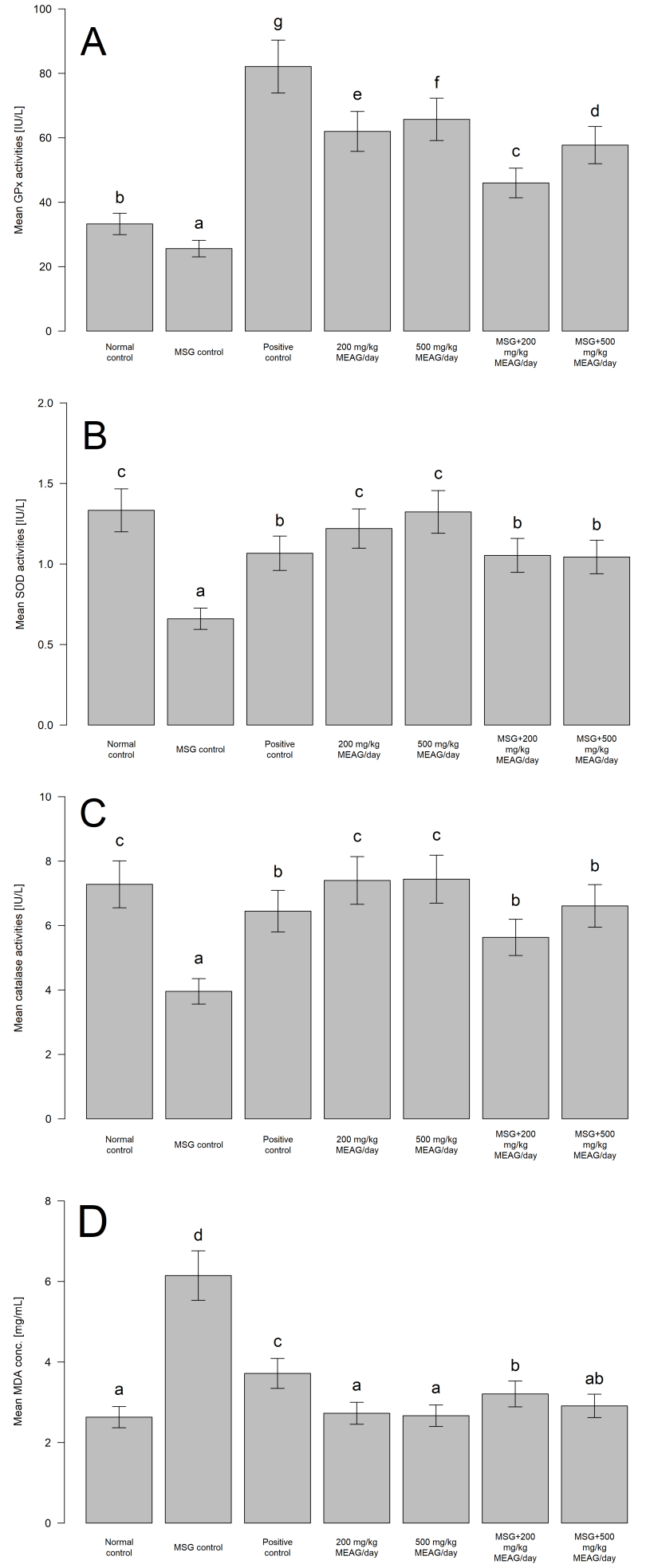

Fig. 4. Activities of monosodium glutamate (MSG) induced rats treated with methanol extract of $A$. gangetica leaves (MEAG), A glutathione peroxidase (GPx); B - superoxide dismutase (SOD); C catalase (CAT), D - malondialdehyde (MDA).

antioxidant phytoconstituents of the extract could have interfered with its antioxidant activities. The DPPH (2,2-diphenyl1-picrylhydrazyl) radical scavenging activity of antioxidant species quantitatively measures the capacity of the antioxidant to scavenge or quench free radicals which play a vital role in preventing oxidative stress and its associated injuries. The increasing percentage of DPPH free radical inhibition of the methanol extract of $A$. gangetica leaves could be attributed 
Table 2. Haematological indices of monosodium glutamate (MSG) induced rats treated with methanol extract of Asystasia gangetica leaves (MEAG)

\begin{tabular}{|c|c|c|c|c|}
\hline Treatment groups & $\begin{array}{r}\mathrm{Hb}^{\mathrm{a}, \mathrm{b}} \\
{[\mathrm{g} / \mathrm{dL}]}\end{array}$ & $\begin{array}{r}\text { PCV } \\
{[\%]}\end{array}$ & $\begin{array}{r}\mathrm{RBC} \\
{\left[10^{12} / \mathrm{L}\right]}\end{array}$ & $\begin{array}{r}\text { WBC } \\
{\left[10^{12} / \mathrm{L}\right]}\end{array}$ \\
\hline Normal control & $15.06 \pm 0.68 \mathrm{c}$ & $45.00 \pm 2.65 \mathrm{~cd}$ & $211.67 \pm 7.64 \mathrm{de}$ & $6766.67 \pm 251.66 \mathrm{e}$ \\
\hline MSG control & $7.97 \pm 0.12 \mathrm{a}$ & $29.10 \pm 1.37 \mathrm{a}$ & $183.33 \pm 2.89 \mathrm{a}$ & $4866.67 \pm 275.51 \mathrm{a}$ \\
\hline Positive control & $11.33 \pm 0.31 b$ & $39.93 \pm 1.72 b$ & $191.67 \pm 2.87 \mathrm{ab}$ & $4833.33 \pm 152.75 \mathrm{a}$ \\
\hline $200 \mathrm{mg} / \mathrm{kg} /$ day MEAG & $14.67 \pm 0.36 \mathrm{c}$ & $45.63 \pm 1.38 \mathrm{~cd}$ & $200.00 \pm 5.00 \mathrm{bcd}$ & $5200.00 \pm 246.41 \mathrm{ab}$ \\
\hline $500 \mathrm{mg} / \mathrm{kg} /$ day MEAG & $16.87 \pm 0.04 \mathrm{c}$ & $49.90 \pm 0.61 \mathrm{f}$ & $217.00 \pm 7.55 \mathrm{e}$ & $5400.00 \pm 200.00 \mathrm{ab}$ \\
\hline $\mathrm{MSG}+200 \mathrm{mg} / \mathrm{kg} /$ day MEAG & $15.73 \pm 0.61 \mathrm{c}$ & $47.97 \pm 2.17 \mathrm{de}$ & $200.00 \pm 8.66 \mathrm{bcd}$ & $5500.00 \pm 181.03 \mathrm{abc}$ \\
\hline $\mathrm{MSG}+500 \mathrm{mg} / \mathrm{kg} /$ day MEAG & $16.17 \pm 0.85 \mathrm{c}$ & $47.00 \pm 1.95 \mathrm{de}$ & $205.00 \pm 5.10 \mathrm{~cd}$ & $6100.00 \pm 220.00 \mathrm{~cd}$ \\
\hline
\end{tabular}

a Abbreviations: $\mathrm{Hb}$ - haemoglobin ; PCV - packed cell volume ; RBC - red blood cells; WBC - white blood cells.

${ }^{b}$ Different letters denote statistically significant difference at $\mathrm{P}<0.05$ level based on Duncan's MLR post hoc test ( $\left.\mathrm{n}=6\right)$

to the increasing concentration of the bioactive antioxidants constituents of the plant extract with the increasing dose. The methanol extract of $A$. gangetica leaves could have scavenged $\mathrm{DPPH}$ free radicals by donating electrons to the DPPH radicals to stabilize and make them less reactive. The DPPH free radical scavenging activities of the methanol extract of $A$. gangetica leaves indicate that it possesses potent antioxidant activities capable of preventing oxidative stress and could be useful in the management of oxidative stress-related disease in line with findings of (Johari and Khong, 2019).

Nitric oxide radical (NO*) is considered a beneficial free radical that occur in a living system due to its contribution to the maintenance of optimal immunological responses against pathogens, antigens and it's role in the neurotransmission of signals in biological systems (Marcocci et al., 1994). However, it could be harmful to the system due to its' increased tendency to react with other chemical species like superoxide ions leading to the formation of highly reactive peroxynitrite anions that could induce oxidative stress. The concentrationdependent nitric oxide radical scavenging activities by the methanol extract of $A$. gangetica leaves could be attributed to the antioxidant constituents of the extract. It suggests that plant extract possesses antioxidant properties that could scavenge excess free radicals such as nitric oxide in the body and prevent oxidative stress. The percentage nitric oxide inhibition by methanol extract of $A$. gangetica leaves is comparably lower than curcumin because of the high $\mathrm{IC}_{50}$ of the extract contrary to the lower $\mathrm{IC}_{50}$ value of curcumin which suggested that an increased dose of methanol extract of $A$. gangetica leaves is required to attain higher antioxidant activity capable of preventing oxidative stress. This is in disagreement with the finding of (Somanathan et al., 2015).

The antioxidant enzymes activities play a major role in neutralizing and quenching oxidative attacks of free radicals on vital organs, tissues, and other biomolecules thereby reducing the extent of oxidative damage associated with free radicals attack. The significant reductions in the glutathione peroxidase (GPx), superoxide dismutase (SOD), and catalase (CAT) activities of the rats challenged with a very high dose of monosodium glutamate without any treatments indicated that the MSG induction elicited increased amounts of reactive free radicals that depleted these circulating antioxidant enzymes, reduced their activities and made the rats vulnerable to oxidative damage. The reductions in GPx, SOD, and CAT activities in the rats challenged with a high dose of MSG without treatment are indicatives of oxidative stress which is consistent with the earlier report by Singh and Ahluwalia (2003) that MSG induces oxidative stress in animals by depleting endogenous antioxidant enzymes concentrations which results to their reduced activities. The reductions in the antioxidant enzymes activities in rats administered a high dose of MSG are in line with findings of (Shukry et al., 2020) who reported high levels of oxidative markers besides reductions in antioxidant enzymes activities.

The high levels of glutathione peroxidase, superoxide dismutase, and catalase activities observed in the extract control groups without MSG administration showed that the methanol extract of $A$. gangetica leaves stimulates and stabilizes the endogenous antioxidant enzymes activities and could be potent in managing oxidative stress and its associated health consequences. The antioxidant components such as flavonoids, total phenols, vitamin $\mathrm{C}$, and $\beta$-carotene possibly contributed to optimizing the activities of the antioxidant enzymes and made the extract control rats better placed to neutralize free radicals attack than the normal control rats because of their high antioxidant activities. Similarly, treatment of the curative groups with graded doses of the methanol extract of $A$. gangetica leaves greatly reversed the high level of oxidative stress elicited by the MSG in the untreated rats and agrees with the findings of (El Kotb et al., 2020). The curative groups exhibited significantly increased levels of antioxidant enzymes (glutathione peroxidase, superoxide dismutase, and catalase) activities relative to the untreated group but very close to the normal control rats in line with the findings of (Shukry et al., 2020). These increases in the GPx, SOD, and CAT activities in the methanol extract of $A$. gangetica leaves treated MSG challenged rats indicated that these rats experienced a reduced degree of MSG toxicity to their various organs, tissues, and biomolecules due to their increased ability to reduce or prevent oxidative damage associated with the administration of high doses of MSG.

The increased levels of malondialdehyde (MDA) in the untreated rats elicited by MSG administration further showed that MSG caused an increased level of oxidative stress in the rats possibly via the depletion of the circulating antioxidant enzymes levels and predisposed them to free radical attack. The increased lipid peroxidation in the MSG control rats could have triggered oxidative attacks on proteins, nucleic acids, membranes and injury to the liver and kidneys of the affected rats. However, the concentration-dependent significant reductions in the levels of MDA concentrations in the extract controls and rats challenged with high doses of MSG but treated with graded doses of methanol extract of A. gangetica leaves could be attributed to the antioxidant activities exhibited by its well-known antioxidant components like flavonoids, carotenoids, and vitamin $\mathrm{C}$. The high antilipid peroxidative effects elicited by the methanol extract of A. gangetica leaves against MSG-induced oxidative stress sug- 
gests that it is effective in the management of oxidative stress, prevention of various health conditions and diseases associated with oxidative stress.

The significant reduction in the haematological indices including haemoglobin $(\mathrm{Hb})$, packed cell volume $(\mathrm{PCV})$, and red blood cell (RBC) count of the MSG control rats indicated that MSG had adverse effects on the haematological indices which resulted in the rats becoming anemic and unable transport oxygenated blood efficiently because of reduced $\mathrm{Hb}$ levels. The MSG could cause reductions in the $\mathrm{Hb}, \mathrm{PCV}$, and $\mathrm{RBC}$ via a haemolytic attack on the RBC, and destruction or impairment of the ability of the erythropoietic cell to replenish the circulating red blood cells. The MSG control rats also had a very low level of white blood cell (WBC) count which suggest that the MSG control rats could have experienced compromised immune system due to insufficient white blood cells. The decreases in the $\mathrm{Hb}, \mathrm{PCV}, \mathrm{RBC}$, and WBC counts of the MSG-induced untreated rats are in line with the findings of (Al-Harbi et al., 2014). However, the elevated levels of $\mathrm{Hb}$, $\mathrm{PCV}, \mathrm{RBC}$, and WBC counts of the extract groups, and curative groups treated with graded doses of methanol extract of $A$. gangetica leaves could be attributed to the haematoprotective effects of the methanol extract of $A$. gangetica leaves. These findings are consistent with the findings of (Al-Harbi et al., 2014). The antioxidants constituent of the methanol extract could have induced haemolysis of the red blood cells and stimulated the erythropoietic cells to replenish lost red blood cells rapidly which would maintain normal haemoglobin and packed cell volume required for normal haematological functions. Besides, the phytoconstituents in the extract would have positively impacted the bone marrow and enable it to maintain normal white blood cell counts essential for optimal immunological responses.

\section{CONCLUSION}

The findings from this study have shown that $A$. gangetica leaf extract has significant antioxidants and haematoprotective properties that may be of pharmacological value in the management of oxidative stress-related diseases and anemia. However, further studies are required to isolate and characterize the bioactive compounds responsible for the observed antioxidants and haematological effects. There is also need to assess its toxicological effects.

\section{REFERENCES}

Aebi, H. (1983). Catalase, in H. Bergmeyer (ed.), Methods of enzymatic analysis, Verlag Chemie, Weinhem, pp. 273-285.

Akah, P., Ezike, A., Nwafor, S., Okoli, C. and Enwerem, N. (2003). Evaluation of the anti-asthmatic property of Asystasia gangetica leaf extracts, Journal of Ethnopharmacology 89(1): 25-36.

Al-Harbi, M. S., El-Shenawy, N. S. and Al-Weail, N. O. S. (2014). Effect of monosodium glutamate on oxidative damage in male mice: Modulatory role of vitamin C, 36(4): 11 .

Dacie, J. V. and Lewis, S. M. (1991). Practical haematology, Churchill Livingstone, Edinburgh; New York. OCLC: 23733082.

El Kotb, S. M., El-ghazouly, D. E.-s. and Ameen, O. (2020). The potential cytoprotective effect of vitamin $C$ and vitamin $E$ on monosodium glutamate-induced testicular toxicity in rats, Alexandria Journal of Medicine 56(1): 134-147.

Hatano, T., Kagawa, H., Yasuhara, T. and Okuda, T. (1988). Two new flavonoids and other constituents in licorice root. Their relative astringency and radical scavenging effects., Chemical and Pharmaceutical Bulletin 36(6): 2090-2097.

Jaeger, R. and Cuny, E. (2016). Terpenoids with special pharmacological significance: A review, Natural Product Communications 11(9): 1934578X1601100.

Johari, M. A. and Khong, H. Y. (2019). Total phenolic content and an- tioxidant and antibacterial activities of Pereskia bleo, Advances in Pharmacological Sciences 2019: 1-4.

Kessler, M., Ubeaud, G. and Jung, L. (2010). Anti- and pro-oxidant activity of rutin and quercetin derivatives, Journal of Pharmacy and Pharmacology 55(1): 131-142.

Khalaf, H. A. and Arafat, E. A. (2015). Effect of different doses of monosodium glutamate on the thyroid follicular cells of adult male albino rats: a histological study, International Journal of Clinical and Experimental Pathology 8(12): 15498-15510.

Marcocci, L., Maguire, J., Droylefaix, M. and Packer, L. (1994). The nitric oxide-scavenging properties of Ginkgo biloba extract EGb 761, Biochemical and Biophysical Research Communications 201(2): 748755.

Mugabo, P. and Raji, I. A. (2013). Effects of aqueous leaf extract of Asystasia gangetica on the blood pressure and heart rate in male spontaneously hypertensive Wistar rats, BMC Complementary and Alternative Medicine 13(1): 283.

Nagata, M. and Yamashita, I. (1992). Simple method for simultaneous determination of chlorophyll and carotenoids in tomato fruit., Nippon Shokuhin Kogyo Gakkaishi 39(10): 925-928.

Omaye, S. T., David Turnbull, J. and Sauberlich, H. E. (1979). [1] Selected methods for the determination of ascorbic acid in animal cells, tissues, and fluids, Methods in Enzymology, Vol. 62, Elsevier, pp. 3-11.

Omonije, O. O., Saidu, A. N. and Muhammad, H. L. (2020). Antioxidant and hypolipidemic effects of methanolic root extract of Chromolaena odorata in alloxan-induced diabetic rats, Iranian Journal of Toxicology 14(2): $63-70$.

Sama, K., Sivaraj, R. and Salam, H. A. (2013). Pharmacognostical and phytochemical screening of Asystasia gangetica (Chinese violet), p. 3.

Shukry, M., El-Shehawi, A. M., El-Kholy, W. M., Elsisy, R. A., Hamoda, H. S., Tohamy, H. G., Abumandour, M. M. and Farrag, F. A. (2020). Ameliorative effect of graviola (Annona muricata) on mono sodium glutamate-induced hepatic injury in rats: Antioxidant, apoptotic, antiinflammatory, lipogenesis markers, and histopathological studies, Animals 10(11): 1996.

Singh, K., Sharma, J., Kaur, A. and Ahluwalia, P. (2011). Alteration upon oral ingestion of monosodium glutamate in various lipid and lipoprotein fractions in serum of adult male rat, Journal of Life Sciences 3(1): 1721.

Somanathan, S., Ranganayakulu, D. and Jayaveera, K. (2015). In-vtiro antioxidant activities of Asystasia gangetica leaf extract, World journal of pharmacy and pharmaceutical sciences 4(2): 1228-1239.

Ugur Calis, I., Turgut Cosan, D., Saydam, F., Kerem Kolac, U., Soyocak, A., Kurt, H., Veysi Gunes, H., Sahinturk, V., Sahin Mutlu, F., Ozdemir Koroglu, Z. and Degirmenci, I. (2016). The effects of monosodium glutamate and tannic acid on adult rats, Iranian Red Crescent Medical Journal 18(10): e37912.

Ursini, F., Maiorino, M. and Gregolin, C. (1985). The selenoenzyme phospholipid hydroperoxide glutathione peroxidase, Biochimica et Biophysica Acta (BBA) - General Subjects 839(1): 62-70.

Wallin, B., Rosengren, B., Shertzer, H. and Camejo, G. (1993). Lipoprotein oxidation and measurement of thiobarbituric acid reacting substances formation in a single microtiter plate: its use for evaluation of antioxidants, Analytical Biochemistry 208(1): 10-15.

Xin, Z., Waterman, D., Hemken, R. and Harmon, R. (1991). Effects of copper status on neutrophil function, superoxide dismutase, and copper distribution in steers, Journal of Dairy Science 74(9): 3078-3085. 